\title{
Ultra-processed foods, protein leverage and energy intake in the USA
}

\author{
Euridice Martínez Steele ${ }^{1,2}$, David Raubenheimer ${ }^{3}$, Stephen J Simpson ${ }^{3}$, \\ Larissa Galastri Baraldi ${ }^{1,2}$ and Carlos A Monteiro ${ }^{1,2, *}$ \\ 'Department of Nutrition, School of Public Health, University of São Paulo, Av. Dr Arnaldo 715, São Paulo, SP 01246- \\ 907, Brazil: ${ }^{2}$ Center for Epidemiological Studies in Health and Nutrition, University of São Paulo, São Paulo, Brazil: \\ ${ }^{3}$ Charles Perkins Centre and School of Life and Environmental Sciences, The University of Sydney, Sydney, Australia
}

Submitted 30 0ctober 2016: Final revision received 18 May 2017: Accepted 5 June 2017: First published online 16 0ctober 2017

\begin{abstract}
Objective: Experimental studies have shown that human macronutrient regulation minimizes variation in absolute protein intake and consequently energy intake varies passively with dietary protein density ('protein leverage'). According to the 'protein leverage hypothesis' (PLH), protein leverage interacts with a reduction in dietary protein density to drive energy overconsumption and obesity. Worldwide increase in consumption of ultra-processed foods (UPF) has been hypothesized to be an important determinant of dietary protein dilution, and consequently an ecological driving force of energy overconsumption and the obesity pandemic. The present study examined the relationships between dietary contribution of $\mathrm{UPF}$, dietary proportional protein content and the absolute intakes of protein and energy.

Design: National representative cross-sectional study.

Setting: National Health and Nutrition Examination Survey 2009-2010.

Subjects: Participants ( $n$ 9042) aged $\geq 2$ years with at least one day of 24 h dietary recall data.

Results: We found a strong inverse relationship between consumption of UPF and dietary protein density, with mean protein content dropping from 18.2 to $13.3 \%$ between the lowest and highest quintiles of dietary contribution of UPF. Consistent with the PLH, increase in the dietary contribution of UPF (previously shown to be inversely associated with protein density) was also associated with a rise in total energy intake, while absolute protein intake remained relatively constant.

Conclusions: The protein-diluting effect of UPF might be one mechanism accounting for their association with excess energy intake. Reducing UPF contribution in the US diet may be an effective way to increase its dietary protein concentration and prevent excessive energy intake.
\end{abstract}

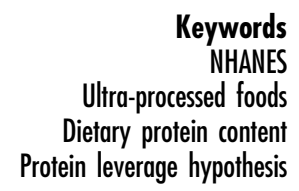

Keywords

NHANES

Dietary protein content

Protein leverage hypothesis
For many decades, beginning with the altercation between Ancel Keys and John Yudkin ${ }^{(1)}$, the scientific community has debated whether the principal driver of obesity is the excessive consumption of fats or carbohydrates ${ }^{(2-5)}$. Historically, the role of protein has received comparatively little attention, both because it is proportionally a minor part of the energy content in the diet and because its absolute and relative intakes have remained more constant over time and across populations than those of either fats or carbohydrates ${ }^{(5-7)}$. More recently, however, attention has turned to dietary protein, particularly in the context of body weight management, with specific emphasis on the role of this macronutrient in appetite regulation ${ }^{(8,9)}$.
The fact that all three macronutrients have now been implicated in obesity suggests that there is a need to broaden the focus from specific nutrients to questions of how each contributes both individually and in interaction with others to drive energy overconsumption. In 2005 , Simpson and Raubenheimer postulated the 'protein leverage hypothesis' (PLH) to address this issue. Like numerous other animal species ${ }^{(10-14)}$, human macronutrient regulation minimizes variation in absolute protein intake. Consequently, any factor that causes a decrease in the dietary proportion of protein energy will also result in increased absolute intakes of fats and/or carbohydrates, and total energy; conversely, increased dietary protein will 
result in decreased energy intake ('protein leverage' $)^{(5,15-18)}$. The PLH proposes that this characteristic of human macronutrient regulation has interacted with an extrinsic cause of dietary protein dilution, for example increased availability of cheap low-protein foods, to drive energy overconsumption and the rise in obesity ${ }^{(5,14)}$.

Protein leverage in human subjects is supported by a recently published compendium of experimental studies ${ }^{(15)}$, which shows how decreases in percentage of protein across the range typically seen in human populations with adequate food supply (10-25\% of total energy from protein) resulted in increased intake of energy in the form of either carbohydrates or $\mathrm{fat}^{(5)}$. Increases above $20 \%$ protein yielded a lesser rate of decline in energy intake than from 10 to $20 \%{ }^{(15)}$, as was also found in controlled trials with diets of disguised macronutrient content ${ }^{(16)}$. A recent experimental study, also using diets of disguised macronutrient content, showed an approximately linear increase in both energy intake and body weight change as dietary protein decreased from $25 \%$ to $15 \%$ and $10 \%$ of energy ${ }^{(17)}$. Another experimental study found that relative to $15 \%$ of energy from protein, energy intakes were reduced on a diet of $30 \%$ protein, as predicted by the PLH, but not increased on a diet of $5 \%$ protein $^{(18)}$. A likely explanation for this is that $5 \%$ of energy from protein is lower than seen naturally in human populations with food sufficiency and outside the range of diets to which the species is evolutionarily adapted ${ }^{(14,15)}$. Population-level data also support the PLH. In the USA, according to FAOSTAT nutrient availability estimates ${ }^{(6)}$, the dietary protein content gradually decreased from $14 \%$ of total energy in 1961 to $12.5 \%$ in 2000 . In this situation, maintaining the absolute protein intake relatively constant required a $14 \%$ total increase in fat and carbohydrate consumption ${ }^{(5)}$. Another study carried out in the USA with data from the National Health and Nutrition Examination Survey (NHANES) estimated that the drop in relative dietary protein content in normal-weight men from $15.9 \%$ in $1971-1975$ to $15.4 \%$ in $2005-2006$ was associated with a $10 \%$ increase in total daily energy intake ${ }^{(19)}$.

Evidence exists that global food supplies are increasingly becoming dominated by ultra-processed food and drink products ${ }^{(20-24)}$. These are industrial formulations manufactured mostly or entirely from ingredients derived from constituents of foods and additives. These components are blended and processed to make ultra-processed foods hyper-palatable, provide novel sensory experiences and even imitate sensorial qualities of unprocessed or minimally processed foods and their culinary preparations, amplifying reward and suppressing satiety ${ }^{(25-27)}$. Given the disparity in cost of the different macronutrients, it makes economic sense for food processors to replace expensive protein with cheaper carbohydrates and fats ${ }^{(28)}$. Ultraprocessed food and drink products could therefore play an important role in determining the relative dietary protein content ( $\%$ of total energy intake), trapping people in a suboptimal diet in which attempting to maintain absolute protein intake drives an increase in energy intake ${ }^{(5)}$.

In the present study, we examine how the consumption of ultra-processed food and drink products (hereafter denoted simply as 'ultra-processed foods') is associated with the relative dietary protein content and the absolute energy and protein intakes of the US diet, and test whether the relationships fit the predictions of the PLH model.

\section{Materials and methods}

\section{Data source, population and sampling}

We used nationally representative data from the 20092010 NHANES, specifically the dietary component What We Eat in America ${ }^{(29)}$.

NHANES is a continuous, nationally representative, cross-sectional survey of non-institutionalized, civilian US residents ${ }^{(30)}$. The NHANES sample was obtained by using a complex, stratified, multistage probability cluster sampling design, based on the selection of counties, blocks, households and the number of people within households ${ }^{(30)}$. To improve the estimate precision and reliability, NHANES 2009-2010 oversampled the following subgroups: Hispanic, non-Hispanic Black, non-Hispanic White and Other persons at or below $130 \%$ of the federal poverty level; and non-Hispanic White and Other persons aged $\geq 80$ years $^{(30)}$.

The survey included an interview conducted in the home and a subsequent health examination performed at a mobile examination centre. All NHANES examinees were eligible for two $24 \mathrm{~h}$ dietary recall interviews. The first dietary recall interview was collected in-person in the mobile examination centre ${ }^{(31)}$, while the second was collected by telephone 3 to $10 \mathrm{~d}$ later ${ }^{(32)}$. Dietary interviews were conducted by trained interviewers using the validated $^{(33-35)}$ US Department of Agriculture Automated Multiple-Pass Method ${ }^{(36)}$. For children under 9 years of age, the interview was conducted with a proxy; for children between 6 and 8 years of age, in the presence of the child. Children aged 9 to 11 years provided their own data assisted by an adult household member (assistant). The preferred proxy/assistant was the most knowledgeable person about the child's consumption the day before the interview. If the child had more than one caregiver, several individuals could contribute to the intake data ${ }^{(31,32)}$.

Among the 13272 people screened in NHANES 20092010, 10537 (79.4\%) participated in the household interview and $10253(77.3 \%)$ also participated in the health examination at the mobile examination centre $^{(37)}$. Of these, 9754 individuals provided one day of complete dietary intakes and 8406 provided two days ${ }^{(38)}$.

We evaluated 9042 survey participants aged $\geq 2$ years who had at least one day of $24 \mathrm{~h}$ dietary recall data and had not been breast-fed on either of the two days. These individuals had similar sociodemographic characteristics 
(in terms of gender, age, race/ethnicity, family income and education) to the full sample of 9787 interviewed participants aged $\geq 2$ years.

\section{Food classification according to processing}

We classified all recorded food items (4981 different Food Codes were consumed in cycle 2009-2010) according to NOVA, a food classification based on the extent and purpose of industrial food processing ${ }^{(25,26,39)}$. This classification includes four groups: 'unprocessed or minimally processed foods' (such as fresh, dry or frozen fruits and vegetables; packaged grains and pulses; grits, flakes or flours made from corn, wheat or cassava; pasta, fresh or dry, made from flours and water; eggs; fresh or frozen meat and fish; and fresh or pasteurized milk); 'processed culinary ingredients' (including sugar, oils, fats, salt and other substances extracted from foods and used in kitchens to season and cook unprocessed or minimally processed foods and to make culinary preparations); 'processed foods' (including canned foods, sugar-coated dry fruits, salted meat products, cheeses and freshly made unpackaged breads, and other ready-to-consume products manufactured with the addition of salt or sugar or other substances of culinary use to unprocessed or minimally processed foods); and 'ultra-processed foods'.

The group of ultra-processed foods, of particular interest in the present study, includes soft drinks, sweet or savoury packaged snacks, confectionery and industrialized desserts, mass-produced packaged breads and buns, poultry and fish nuggets and other reconstituted meat products, instant noodles and soups, and many other ready-to-consume formulations of several ingredients. Besides salt, sugar, oils and fats, these ingredients include food substances not commonly used in culinary preparations, such as modified starches, hydrogenated oils, protein isolates and additives, whose purpose is to imitate sensorial qualities of unprocessed or minimally processed foods and their culinary preparations, or to disguise undesirable qualities of the final product, such as colorants, flavourings, non-sugar sweeteners, emulsifiers, humectants, sequestrants, and firming, bulking, de-foaming, anti-caking and glazing agents. A detailed definition of each NOVA food group and examples of food items classified in each group are shown elsewhere ${ }^{(40)}$. The rationale underlying the classification is described elsewhere ${ }^{(22,41-43)}$.

For all food items (Food Codes) judged to be a handmade recipe, the classification was applied to the underlying ingredients (Standard Reference Codes (SR Codes)) obtained from the US Department of Agriculture Food and Nutrient Database for Dietary Studies (FNDDS) version $5.0^{(44)}$. Further details have been published previously $^{(40)}$.

\section{Assessing energy and protein contents}

For the present study, we used Food Code energy values as provided by NHANES.
For hand-made recipes, we calculated the underlying ingredient (SR Code) energy and protein values using variables from both the FNDDS version $5.0^{(44)}$ and the US Department of Agriculture National Nutrient Database for Standard Reference, Release 24 (SR24) ${ }^{(45)}$.

Protein intake was converted into MJ using the conversion factor $0 \cdot 016736 \mathrm{MJ} / \mathrm{g}$.

\section{Data analysis}

We used all available dietary data for each participant, using means of both recall days when available ( $86 \%$ of participants). Food items were sorted into mutually exclusive food subgroups within unprocessed or minimally processed foods ( $n$ 11), processed culinary ingredients ( $n$ 4), processed foods ( $n$ 4) and ultra-processed foods ( $n$ 17), as shown in Table 1 . First, we evaluated the contributions of each of the NOVA food groups and subgroups to total energy and protein intakes. Thereafter, we calculated the average relative protein content, expressed as a proportion of total energy intake, in the overall US diet and in fractions of this diet composed by each of the NOVA food groups and subgroups. We also calculated the relative protein content of the group of unprocessed or minimally processed foods combined with the group of processed culinary ingredients, as the items belonging to these two groups are usually combined in culinary preparations and therefore consumed together.

We used Gaussian regression to estimate the association of the dietary contribution of ultra-processed foods with the relative dietary protein content (\% of total energy intake) and the absolute energy (MJ) and protein intakes (MJ). Dietary contribution of ultra-processed foods was transformed using restricted cubic spline functions to allow for non-linearity.

Crude and adjusted average dietary protein content and absolute energy and protein intakes were compared across quintiles of the dietary contribution of ultraprocessed foods. Poisson regression was used to evaluate whether the percentage of individuals with relative dietary protein contents lower than $20 \%, 15 \%$ or $10 \%$ of total energy intake decreased across quintiles ${ }^{(46)}$. This decrease was also assessed across demographic subgroups in stratified analysis. Tests of linear trend were performed to evaluate the effect of quintiles as a single continuous variable.

All regression models were adjusted for race/ethnicity (Mexican-American, Other Hispanic, non-Hispanic White, non-Hispanic Black, Other Race including Multi-racial), ratio of family income to poverty (categorized based on Supplemental Nutrition Assistance Program eligibility as $0 \cdot 00-1 \cdot 30,>1 \cdot 30-3.50$ and $\geq 3.50)^{(29)}$ and educational attainment of respondents for participants aged $\geq 20$ years and of the household reference person otherwise $(<12$ years, 12 years and $>12$ years). To take account of different dietary protein content requirements according to age group (5-20, $10-20$ or $10-35 \%$ of total energy), 
different daily protein intake requirements according to sex-age groups $(0.2176,0.3179,0.569,0.7699,0.8703$, 0.9372 or $1.1883 \mathrm{MJ}$ ) and different daily energy intake requirements according to sex-age-physical activity level groups $(4 \cdot 184,5 \cdot 0208,5 \cdot 8576,6.6944,7 \cdot 5312,8.368$, $9 \cdot 2048, \quad 10 \cdot 0416, \quad 10 \cdot 8784, \quad 11 \cdot 7152, \quad 12.552$ or $13.3888 \mathrm{MJ})^{(47)}$, analyses using relative dietary protein content, protein daily intake or energy daily intake as outcomes were accordingly adjusted for these requirements (as dummy variables). As 886 participants had missing values on family income and/or education, adjusted analyses included 8156 individuals. Analysis also adjusting for daily energy intake requirements included 8128 because thirty-one had missing values for physical activity. As the included sample differs across models, results may not always be comparable.

NHANES survey sample weights were used in all analyses to account for differential probabilities of selection for the individual domains, non-response to survey instruments, and differences between the final sample and the total US population. The Taylor series linearization was used for variance estimation to account for the complex sample design and the sample weights ${ }^{(30)}$.

Statistical hypotheses were tested using a two-tailed $P<0.01$ level of significance. Data were analysed using the Stata statistical software package version 12.1.

\section{Results}

Distribution of total energy intake by food group The average US daily energy intake in 2009-2010 was 8.6 MJ, with nearly 3 in $5 \mathrm{MJ}(57.6 \%)$ coming from ultra-processed foods (Table 1). Unprocessed or minimally processed foods contributed $30 \cdot 1 \%$ of total energy intake, processed foods an additional $9.4 \%$ and processed culinary ingredients the remaining $2.9 \%$. The most common ultra-processed foods in terms of energy contribution were breads; soft and fruit drinks; cakes, cookies and pies; salty snacks; frozen and shelf-stable plate meals; pizza; and breakfast cereals. Meat, fruit and milk provided the most energy among unprocessed or minimally processed foods; ham and cheese, the most energy among processed foods; and table sugar and plant oils, the most energy among processed culinary ingredients.

\section{Distribution of total protein intake by food group}

The average US daily protein intake corresponded to $1.3 \mathrm{MJ}$ (Table 1) and almost half (48.7\%) of this intake came from unprocessed or minimally processed foods. Ultra-processed foods contributed $38.3 \%$, processed foods an additional $12 \cdot 8 \%$ and the remaining $0 \cdot 2 \%$ of the protein intake came from processed culinary ingredients. The main sources of protein among unprocessed or minimally processed foods were meat, milk, eggs and fish, while among processed foods they were cheeses and ham and among ultra-processed foods they were breads and frozen and shelf-stable plate meals.

The average protein content in ultra-processed foods (9.5\% of total energy intake) was less than half that in both processed foods $(24.3 \%)$ and unprocessed or minimally processed foods and processed culinary ingredients grouped together $(25 \cdot 3 \%$; Table 1$)$.

\section{Association between dietary contribution of ultra- processed foods and overall dietary protein content} The unadjusted restricted cubic spline Gaussian regression analysis showed an inverse linear association between the dietary contribution of ultra-processed foods and the overall dietary protein content (both expressed as \% of total energy intake; coefficient for linear term $=-0.08$; $95 \%$ CI $-0 \cdot 13,-0 \cdot 03$; Fig. 1). The strength of the association remained similar after adjusting for the sex-age dummies corresponding to groups with different protein content requirements, race/ethnicity, family income and education (coefficient for linear term $=-0.07$; 95\% CI $-0.12,-0.02$; Wald test for linear term $P=0.008$; Wald test for all non-linear terms $P=0 \cdot 05)$. Overall, each increase of 14 percentage points in dietary contribution of ultraprocessed foods was associated with 1 percentage point lower relative dietary protein content.

Consistent with the spline models, across quintiles of the dietary contribution of ultra-processed foods, unadjusted mean dietary protein content decreased substantially and monotonically, from $18.2 \%$ of total energy intake in the lowest quintile to $13.3 \%$ in the highest (Table 2). Across the same quintiles, the proportion of individuals consuming less than $15 \%$ of total energy from protein increased from $25 \cdot 1$ to $73.3 \%$, respectively. An even more pronounced increase was seen in the proportion of individuals consuming less than $10 \%$ of energy from protein, rising from $2 \cdot 8$ to $14.9 \%$, respectively. The increases cut across demographic subgroups although they varied somewhat by subgroup (see the online supplementary material, Supplemental Table 1). The magnitude and the statistical significance of the association between the dietary contribution of ultra-processed foods and the overall dietary protein content did not change with adjustment for age groups with different dietary protein content requirements, race/ethnicity, family income and education.

\section{Association between dietary contribution of ultra- processed foods and absolute energy and protein intakes}

Restricted cubic spline Gaussian analysis suggested a nonlinear association of dietary contribution of ultraprocessed foods with absolute energy intake (Fig. 2(a)), especially the adjusted model (coefficient for linear term $=0 \cdot 044 ; 95 \%$ CI 0.012, 0.076; Wald test for linear term $P=0 \cdot 01$; Wald test for all non-linear terms $P=0 \cdot 009$ ). Total energy intake rose with increases in the dietary 
Table 1 Distribution of total energy and protein intakes according to NOVA food groups, and mean protein content of each food group. US population aged $\geq 2$ years ( $n$ 9042), National Health and Nutrition Examination Survey 2009-2010

\begin{tabular}{|c|c|c|c|c|c|}
\hline \multirow[b]{2}{*}{ Food group } & \multicolumn{2}{|c|}{ Mean energy intake } & \multicolumn{2}{|c|}{ Mean protein intake } & \multirow[b]{2}{*}{$\begin{array}{l}\text { Mean protein } \\
\text { content (\% of energy } \\
\text { from protein) }\end{array}$} \\
\hline & $\begin{array}{l}\text { Absolute } \\
(\mathrm{MJ} / \mathrm{d})\end{array}$ & $\begin{array}{c}\text { Relative } \\
\text { (\% of total } \\
\text { energy intake) }\end{array}$ & $\begin{array}{l}\text { Absolute } \\
(\mathrm{MJ} / \mathrm{d})\end{array}$ & $\begin{array}{c}\text { Relative } \\
\text { (\% of total energy } \\
\text { intake from protein) }\end{array}$ & \\
\hline Unprocessed or minimally processed foods & 2.5 & $30 \cdot 1$ & 0.7 & $48 \cdot 7$ & $27 \cdot 6$ \\
\hline Meat (includes poultry) & 0.7 & 8.4 & 0.4 & 23.7 & $52 \cdot 5$ \\
\hline Fruit and freshly squeezed fruit juices & 0.4 & $5 \cdot 2$ & 0.0 & 1.7 & 4.9 \\
\hline Milk and plain yoghurt & 0.4 & 4.9 & 0.1 & 8.6 & 28.4 \\
\hline Grains & $0 \cdot 2$ & 2.9 & 0.0 & 1.9 & $10 \cdot 5$ \\
\hline Roots and tubers & $0 \cdot 1$ & 1.6 & 0.0 & 1.0 & $10 \cdot 8$ \\
\hline Eggs & 0.1 & 1.5 & 0.0 & $3 \cdot 2$ & $36 \cdot 6$ \\
\hline Pasta & $0 \cdot 1$ & 1.4 & 0.0 & 1.4 & 14.2 \\
\hline Legumes & 0.1 & 0.9 & 0.0 & 1.4 & $25 \cdot 6$ \\
\hline Fish and seafood & 0.1 & 0.8 & 0.0 & 2.9 & $68 \cdot 3$ \\
\hline Vegetables & $0 \cdot 1$ & 0.8 & 0.0 & $1 \cdot 2$ & 24.9 \\
\hline Other unprocessed or minimally processed foods* & 0.2 & $1 \cdot 7$ & 0.0 & 1.7 & $30 \cdot 6$ \\
\hline Processed culinary ingredients & 0.3 & $2 \cdot 9$ & 0.0 & 0.2 & 0.8 \\
\hline Sugar† & $0 \cdot 1$ & $1 \cdot 1$ & 0.0 & 0.0 & 0.0 \\
\hline Plant oils & 0.1 & 1.3 & 0.0 & 0.0 & 0.0 \\
\hline Animal fats $\ddagger$ & 0.0 & 0.5 & 0.0 & 0.2 & 3.8 \\
\hline Other processed culinary ingredients§ & 0.0 & 0.04 & 0.0 & 0.02 & $3 \cdot 4$ \\
\hline $\begin{array}{l}\text { Unprocessed or minimally processed foods + } \\
\text { processed culinary ingredients }\end{array}$ & $2 \cdot 7$ & $33 \cdot 0$ & 0.7 & $48 \cdot 9$ & $25 \cdot 3$ \\
\hline Processed foods & 0.9 & $9 \cdot 4$ & 0.2 & $12 \cdot 8$ & $24 \cdot 3$ \\
\hline Cheese & 0.3 & $3 \cdot 7$ & 0.1 & $6 \cdot 2$ & $26 \cdot 7$ \\
\hline Ham and other salted, smoked or canned meat or fish & 0.1 & $1 \cdot 3$ & 0.1 & $3 . \overline{7}$ & 49.9 \\
\hline Vegetables and other plant foods preserved in brine & $0 \cdot 1$ & 0.7 & 0.0 & 0.8 & $16 \cdot 1$ \\
\hline Other processed foods $\|$ & 0.4 & 3.7 & 0.0 & $2 \cdot 1$ & $9 \cdot 3$ \\
\hline Ultra-processed foods & $5 \cdot 0$ & $57 \cdot 6$ & 0.5 & $38 \cdot 3$ & 9.5 \\
\hline Breads & 0.8 & 9.7 & $0 \cdot 1$ & 8.6 & $13 \cdot 6$ \\
\hline Soft and fruit drinks $\uparrow$ & 0.6 & $6 \cdot 8$ & 0.0 & 0.7 & $5 \cdot 4$ \\
\hline Cakes, cookies and pies & 0.5 & 5.5 & 0.0 & 2.5 & $5 \cdot 8$ \\
\hline Salty snacks & 0.4 & 4.4 & 0.0 & $2 \cdot 3$ & $7 \cdot 2$ \\
\hline Frozen and shelf-stable plate meals & 0.3 & 3.9 & 0.1 & $5 \cdot 2$ & 18.4 \\
\hline Pizza (ready-to-eat/heat) & 0.3 & $3 \cdot 3$ & $0 \cdot 1$ & 3.9 & $16 \cdot 6$ \\
\hline Breakfast cereals & 0.2 & 3.0 & 0.0 & 1.7 & 8.6 \\
\hline Sauces, dressings and gravies & 0.2 & $2 \cdot 6$ & 0.0 & 0.5 & 8.5 \\
\hline Reconstituted meat or fish products & 0.2 & $2 \cdot 3$ & 0.1 & 3.9 & 31.7 \\
\hline Ice cream and ice pops & 0.2 & $2 \cdot 3$ & 0.0 & 1.2 & 6.9 \\
\hline Sweet-snacks & 0.2 & $2 \cdot 3$ & 0.0 & 0.9 & 4.6 \\
\hline Milk-based drinks & 0.1 & 1.9 & 0.0 & $2 \cdot 1$ & 18.2 \\
\hline Desserts** & $0 \cdot 1$ & 1.8 & 0.0 & 0.3 & $2 \cdot 7$ \\
\hline French fries and other potato products & $0 \cdot 2$ & 1.7 & 0.0 & 0.7 & $5 \cdot 1$ \\
\hline Sandwiches and hamburgers on bun (ready-to-eat/heat) & $0 \cdot 1$ & 1.4 & 0.0 & 1.9 & $19 \cdot 2$ \\
\hline Instant and canned soups & 0.1 & 0.9 & 0.0 & $1 \cdot 1$ & $32 \cdot 3$ \\
\hline Other ultra-processed foods $† \dagger$ & 0.3 & $3 \cdot 7$ & 0.0 & 0.6 & $2 \cdot 9$ \\
\hline Total & $8 \cdot 6$ & $100 \cdot 0$ & 1.3 & $100 \cdot 0$ & $15 \cdot 8$ \\
\hline
\end{tabular}

*Including nuts and seeds (unsalted); yeast; dried fruits (without added sugars) and vegetables; non-pre-sweetened, non-whitened, non-flavoured coffee and tea; coconut water and flesh; home-made soup and sauces; flours; tapioca.

tIncluding honey, molasses, maple syrup (100\%).

łlncluding butter, lard and cream.

§Including starches; coconut and milk cream; baking chocolate, cocoa powder and gelatine powder; vinegar; baking powder and baking soda.

|l Including salted or sugared nuts and seeds; peanut, sesame, cashew and almond butter or spread; beer and wine.

IIncluding energy drinks, sports drinks, non-alcoholic wine.

**Including ready-to-eat and dry-mix desserts such as pudding.

††lncluding soya products such as meatless patties and fish sticks; baby food and baby formula; dips, spreads, mustard and catsup; margarine; sugar substitutes, sweeteners and all syrups (excluding $100 \%$ maple syrup); distilled alcoholic drinks.

contribution of ultra-processed foods up until this contribution reached nearly $70 \%$ of total energy intake. Further increases in the contribution of ultra-processed foods were associated with slight reductions in total energy intake. These results were consistent with the analysis across quintiles of the dietary contribution of ultraprocessed foods (Table 3), which showed that adjusted mean energy intake increased between the first (8.2 MJ) and the fourth quintiles $(8.9 \mathrm{MJ})$ while decreasing slightly in quintile $5(8.8 \mathrm{MJ})$. Despite the statistically nonsignificant slight decrease in energy intake between quintiles 4 and 5 (adjusted Wald test $P=0 \cdot 5$ ), there was an overall positive significant linear trend across all quintiles $(P<0 \cdot 001)$. 
In combination with falling relative dietary protein content and rising total energy intake, total protein intake remained much the same with increases in the dietary contribution of ultra-processed foods up until this contribution reached nearly $40 \%$ of total energy intake. Further increases in the contribution of ultra-processed foods were first associated with slight declines in total protein intake (up to the point that ultra-processed foods represented nearly $70 \%$ of total energy intake) and then with greater declines as ultra-processed energy intakes fell away (Fig. 2(b)). Similar results were obtained in adjusted models (coefficient for linear term $=0.002 ; 95 \% \mathrm{CI}-0 \cdot 005$, +0.008 ; Wald test for linear term $P=0.5$; Wald test for all non-linear terms $P<0.001)$. Adjusted mean total protein intake changed little from the first to the third quintiles of dietary contribution of ultra-processed foods while a slight

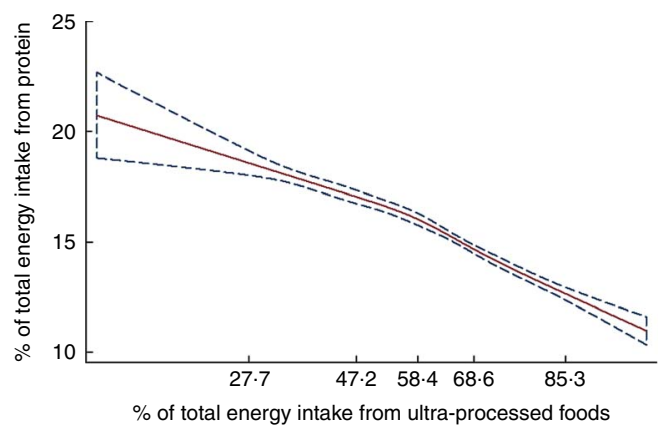

Fig. 1 Regression of dietary protein content $v$. the dietary contribution of ultra-processed foods evaluated by restricted cubic splines ( - , predicted values; --.-.., $95 \% \mathrm{Cl}$ ), among the US population aged $\geq 2$ years ( $n$ 9042), National Health and Nutrition Examination Survey 2009-2010. The values shown on the $x$-axis correspond to the 5th, 27.5th, 50th, 72.5th and 95th percentiles for percentage of total energy from ultraprocessed foods (knots). Coefficient for linear term $=-0.08$ $(95 \% \mathrm{Cl}-0.13,-0.03)$. There was little evidence of nonlinearity in the restricted cubic spline model (Wald test for linear term $P=0.006$; Wald test for all non-linear terms $P=0.07$ ) decline was observed from the third to the fifth quintile (Table 3).

\section{The protein leverage bypothesis}

Figure 3 presents a synthesis of our results which addresses the protein leverage model. The positively sloped radials show the ratio of protein energy to non-protein energy in the diet, and the negative diagonals show the total energy intakes associated with each quintile of the dietary contribution of ultra-processed foods. The vertical black line represents the prediction under $100 \%$ protein energy prioritization (i.e. constant absolute protein energy intake leverages excess non-protein energy intake), assuming a target protein energy intake of $1.4 \mathrm{MJ}$ (determined as quintile 1 adjusted mean, Table 3). The horizontal black line represents the model of $100 \%$ non-protein prioritization, assuming a non-protein energy intake target of $6.7 \mathrm{MJ}$ (quintile 1 adjusted mean). The black negative diagonal line represents the third alternative model of total energy prioritization (i.e. constant total energy intake regardless of the relative dietary protein content), assuming in this illustrative case a total energy intake target of $8.2 \mathrm{MJ}$ (quintile 1 adjusted mean value).

The data strongly suggest protein prioritization, as demonstrated in experimental studies ${ }^{(15-18)}$, which is consistent with the PLH. First, absolute protein energy intakes were relatively constant (vertical black line) across ultraprocessed food dietary contribution quintiles, consistent with the strong human protein appetite. Second, as the percentage of dietary energy from protein decreased (positive radials, $18 \cdot 2-13 \cdot 3 \%$ ), in this case corresponding with increasing ultra-processed food consumption (quintiles 1-5), the intake of non-protein energy and consequently total energy (negative diagonals, $8 \cdot 2-8.8 \mathrm{MJ}$ ) increased. There is, by contrast, no correspondence to the prediction of nonprotein prioritization (in which non-protein energy intake remains constant across ultra-processed food quintiles) or

Table 2 Indicators of dietary protein content according to the dietary contribution of ultra-processed foods. US population aged $\geq 2$ years $(n$ 9042), National Health and Nutrition Examination Survey 2009-2010

\begin{tabular}{|c|c|c|c|c|c|c|c|c|c|c|c|c|c|}
\hline \multirow{2}{*}{\multicolumn{3}{|c|}{$\begin{array}{l}\text { Dietary contribution of ultra-processed } \\
\text { foods (\% of total energy intake) }\end{array}$}} & \multirow{2}{*}{\multicolumn{2}{|c|}{$\begin{array}{l}\% \text { of total energy } \\
\text { intake from protein }\end{array}$}} & \multicolumn{9}{|c|}{ Indicators } \\
\hline & & & & & \multicolumn{3}{|c|}{$\begin{array}{l}\text { Diets with less than } \\
20 \% \text { of total energy } \\
\text { intake from protein }\end{array}$} & \multicolumn{3}{|c|}{$\begin{array}{l}\text { Diets with less than } \\
15 \% \text { of total energy } \\
\text { intake from protein }\end{array}$} & \multicolumn{3}{|c|}{$\begin{array}{l}\text { Diets with less than } \\
10 \% \text { of total energy } \\
\text { intake from protein }\end{array}$} \\
\hline Quintile & Mean & Range & Mean & Adj. mean† & $\%$ & PR $\ddagger$ & PRadj§ & $\%$ & PR $\ddagger$ & PRadj§ & $\%$ & PR $\ddagger$ & PRadj§ \\
\hline 1st (n 1852) & 32.5 & $0-42 \cdot 8$ & $18 \cdot 1$ & $18 \cdot 2$ & $70 \cdot 4$ & 1.0 & 1.0 & $25 \cdot 1$ & 1.0 & 1.0 & $2 \cdot 8$ & 1.0 & 1.0 \\
\hline 2nd (n 1846) & $48 \cdot 6$ & $42 \cdot 8-54 \cdot 2$ & $16 \cdot 9$ & $16 \cdot 9$ & $80 \cdot 9$ & $1 \cdot 1$ & $1 \cdot 1$ & $32 \cdot 1$ & 1.3 & $1 \cdot 3$ & 1.8 & 0.6 & 0.8 \\
\hline $3 r d(n 1736)$ & $58 \cdot 3$ & $54 \cdot 2-62 \cdot 8$ & $16 \cdot 0$ & $16 \cdot 0$ & $89 \cdot 1$ & 1.3 & 1.3 & 41.7 & 1.7 & 1.7 & $2 \cdot 2$ & 0.8 & 0.9 \\
\hline 4th $(n 1733)$ & $67 \cdot 2$ & $62 \cdot 8-72 \cdot 2$ & $14 \cdot 8$ & $14 \cdot 8$ & $95 \cdot 6$ & 1.4 & 1.4 & $56 \cdot 0$ & $2 \cdot 2$ & $2 \cdot 3$ & 3.5 & 1.3 & $1 \cdot 3$ \\
\hline 5 th $(n 1875)$ & 80.7 & $72 \cdot 2-100 \cdot 0$ & $13 \cdot 2^{*}$ & $13 \cdot 3^{*}$ & $97 \cdot 2$ & $1.4^{*}$ & $1.4^{*}$ & $73 \cdot 3$ & $2 \cdot 9^{\star}$ & $2 \cdot 9^{*}$ & 14.9 & $5 \cdot 4^{\star}$ & $6 \cdot 1^{*}$ \\
\hline Total (n 9042) & 57.5 & $0-100 \cdot 0$ & $15 \cdot 8$ & $15 \cdot 8$ & $86 \cdot 6$ & - & - & $45 \cdot 6$ & - & - & $5 \cdot 0$ & - & - \\
\hline
\end{tabular}

${ }^{*}$ Significant linear trend across all quintiles $(P \leq 0.001)$.

†Adjusted for protein \% requirements (dummy variables), race/ethnicity (Mexican-American, Other Hispanic, non-Hispanic White, non-Hispanic Black and Other Race - including Multi-racial), ratio of family income to poverty (categorized based on Supplemental Nutrition Assistance Program eligibility as $0.00-1.30$, $>1.30-3.50$ and $\geq 3.50$ ) and educational attainment ( $<12$ years, 12 years and $>12$ years).

$\ddagger P R=$ prevalence ratios estimated using Poisson regression.

$\S P R a d j=$ prevalence ratios adjusted for percentage protein requirements (dummy variables), race/ethnicity, ratio of family income to poverty and educational attainment as above $(n 8156)$. 
(a)

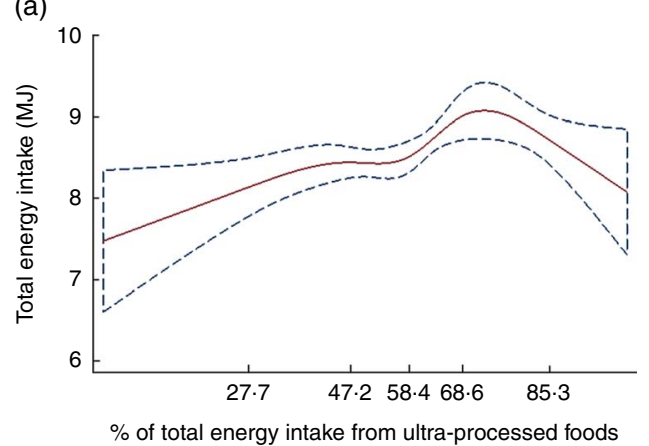

(b)

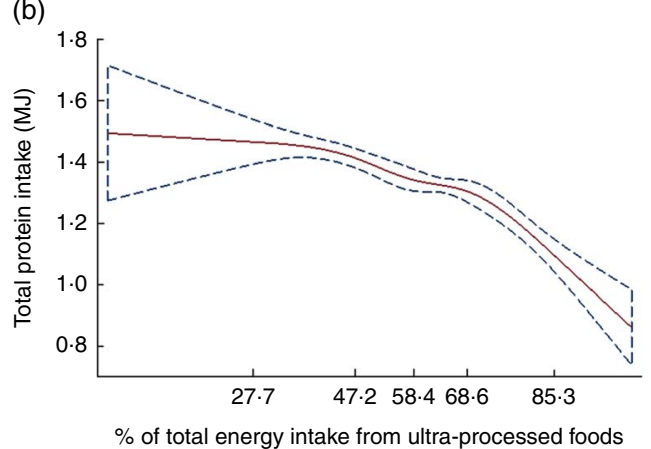

Fig. 2 Regression of total energy intake and total protein intake $v$. the dietary contribution of ultra-processed foods, evaluated by restricted cubic splines (__ , predicted values; -...., $95 \% \mathrm{Cl}$ ), among the US population aged $\geq 2$ years $(n 9042)$, National Health and Nutrition Examination Survey 2009-2010. (a) The values shown on the $x$-axis correspond to the 5th, 27.5th, 50th, 72.5th and 95th percentiles for percentage of total energy from ultra-processed foods (knots). Coefficient for linear term $=0.024(95 \% \mathrm{Cl} 0.002$, 0.046 ). There was little evidence of linearity in the restricted cubic spline model (Wald test for linear term $P=0.035$; Wald test for all non-linear terms $P=0.049$ ). (b) The values shown on the $x$-axis correspond to the 5th, 27.5th, 50th, 72.5th and 95th percentiles for percentage of total energy from ultra-processed foods (knots). Coefficient for linear term $=-0.001(95 \% \mathrm{Cl}-0.007,0.004)$. There was little evidence of linearity in the restricted cubic spline model (Wald test for linear term $P=0.7$; Wald test for all non-linear terms $P=0.0009$; Wald test for all terms $P<0.001$ )

Table 3 Total energy and protein intakes according to the dietary contribution of ultra-processed foods. US population aged $\geq 2$ years ( $n$ 9042), National Health and Nutrition Examination Survey 20092010

\begin{tabular}{|c|c|c|c|c|}
\hline \multirow{2}{*}{$\begin{array}{l}\text { Quintile of dietary contribution of } \\
\text { ultra-processed foods } \\
\text { (\% of total energy intake) }\end{array}$} & \multicolumn{2}{|c|}{$\begin{array}{l}\text { Total energy } \\
\text { intake (MJ) }\end{array}$} & \multicolumn{2}{|c|}{$\begin{array}{l}\text { Total protein } \\
\text { intake (MJ) }\end{array}$} \\
\hline & Mean & $\begin{array}{c}\text { Adj. } \\
\text { mean† }\end{array}$ & Mean & $\begin{array}{l}\text { Adj. } \\
\text { mean } \neq\end{array}$ \\
\hline 1st (n 1852) & $8 \cdot 2$ & $8 \cdot 2$ & 1.5 & 1.4 \\
\hline 2nd ( $n$ 1846) & 8.4 & 8.5 & 1.4 & 1.4 \\
\hline 3rd ( $n$ 1736) & 8.5 & 8.6 & $1 \cdot 3$ & 1.4 \\
\hline 4th (n 1733) & 8.9 & 8.9 & $1 \cdot 3$ & $1 \cdot 3$ \\
\hline 5th (n 1875) & $8 \cdot 9^{\star}$ & $8 \cdot 8^{*}$ & $1 \cdot 2^{*}$ & $1 \cdot 2^{\star}$ \\
\hline Total (n 9042) & $8 \cdot 6$ & $8 \cdot 6$ & 1.3 & 1.3 \\
\hline
\end{tabular}

*Significant linear trend across all quintiles $(P \leq 0.001)$.

†Adjusted for energy requirements (dummy variables), race/ethnicity (Mexican-American, Other Hispanic, non-Hispanic White, non-Hispanic Black and Other Race - including Multi-racial), ratio of family income to poverty (categorized based on Supplemental Nutrition Assistance Program eligibility as $0.00-1.30,>1.30-3.50$ and $\geq 3.50$ ) and educational attainment ( $<12$ years, 12 years and $>12$ years).

$\ddagger$ Adjusted for absolute protein requirements (dummy variables), race/ethnicity, ratio of family income to poverty and educational attainment as above.

total energy prioritization (where total energy intake is independent of macronutrient ratios, in which case the points for ultra-processed food quintiles would align along the black negative diagonal).

\section{Discussion}

In the present analysis of nationally representative data, we provide evidence that ultra-processed foods represent almost $60 \%$ of all energy intake in the US diet and contribute less than $40 \%$ of all protein. Protein represented 1 of every $10 \mathrm{MJ}$ in the average ultra-processed food (9.5\%), far lower than the protein content in either processed foods $(24.3 \%)$ or unprocessed or minimally processed foods and processed culinary ingredients grouped together $(25.3 \%)$. A strong inverse relationship was found between the dietary contribution of ultra-processed foods and the overall dietary protein content. Moreover, the probability of dietary protein content below $15 \%$ increased three times from the lowest to the highest quintile of the dietary contribution of ultra-processed foods and six times for dietary protein content below 10\%. Consistent with the PLH, we observed that increases in the dietary contribution of ultra-processed foods were associated with a dilution of dietary protein density and a rise in total energy intake, while absolute protein intake remained relatively constant. This was seen for increases in ultra-processed food consumption up to values corresponding to approximately $70 \%$ of total energy intake, or up to values found among four-fifths of the US population. Beyond this point, rises in dietary contribution of ultraprocessed foods yielded slight drops in both total energy and protein intakes. A possible explanation for the latter result may be limits in increasing energy intake after a certain level (e.g. as discussed elsewhere ${ }^{(15)}$ ) and other mechanisms triggered by consequences of excessive energy intake such as the accumulation of adipose tissue.

To our knowledge, the present study is the first to establish the relationship of the dietary contribution of ultra-processed foods with the overall dietary protein content and the absolute energy and protein intakes in the USA.

A modest elevation in dietary protein concentration, which could be achieved by a reduction in the consumption of ultra-processed foods, has been predicted by Simpson and Raubenheimer ${ }^{(5)}$ to alleviate the problems of energy overconsumption. At a mechanistic level, this follows both because of protein's influence on appetite control systems, 


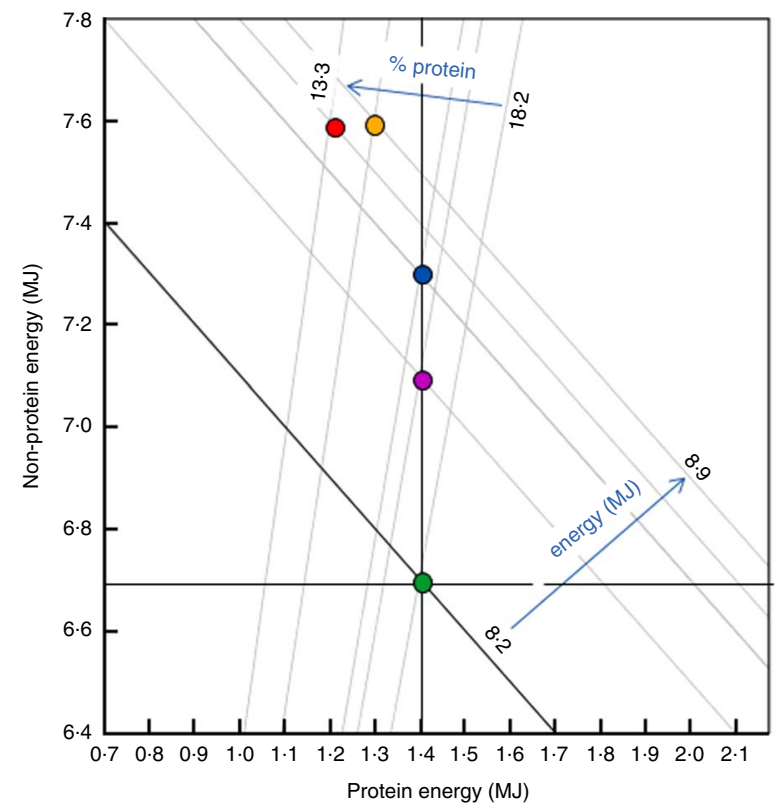

Fig. 3 Macronutrient and energy correlates of the dietary contribution of ultra-processed foods (discretized into quintiles: 0,$1 ; 0,2 ; 0,3 ; 0,4 ; 0,5)$. The negatively sloped diagonals represent daily total energy intakes (calculated as the sum of $\mathrm{X}+\mathrm{Y}$ ) and the positive radials represent the ratio of dietary protein energy to non-protein energy $(X / Y)$. The dark vertical, horizontal and diagonal lines represent alternative models to explain the data. Vertical: complete protein prioritization, in which absolute protein energy intake remains constant with decreasing dietary percentage of protein. Under this scenario, a decrease in dietary percentage of protein (upper blue arrow) leads to an increase in total energy intake (lower blue arrow). Horizontal: complete non-protein prioritization, in which non-protein energy intake remains constant and protein energy intake changes with decreasing dietary percentage of protein. Diagonal: total energy prioritization, in which decreasing dietary percentage of protein is associated with counter-balancing changes in protein and non-protein energy intakes, such that total energy intake is not affected by increasing ultra-processed food contribution in the diet. The data closely fit the protein prioritization model

through reduced postprandial hunger and increased postprandial satiety ${ }^{(8,16)}$, and a concomitant reduction in hyperpalatability from highly palatable, energy-dense fats and sugars, which might also induce energy overconsumption. Our study shows that both processed foods and unprocessed or minimally processed foods combined with processed culinary ingredients provide more than twice as much protein per unit of energy than ultra-processed foods. A reduction in ultra-processed foods should also increase the intake of more healthful, minimally processed foods such as milk, fruits and nuts, and freshly prepared dishes based on whole grains and vegetables, which would provide additional health benefits ${ }^{(48)}$.

Few studies have assessed the impact of food processing levels on the protein nutrient profile of the US diet. One study ${ }^{(49)}$ based on NHANES 2003-2008 data employed a food classification system ${ }^{(50)}$ including two food groups which are mostly ultra-processed foods ('Mixtures of combined ingredients' and 'Ready-to-eat'). That study showed that these two food groups together contributed about half of total energy intake and $40 \%$ of energy intake from protein. An investigation in Canada, using 2001 household purchasing data, found that ultraprocessed foods are low in protein and that the relative dietary protein content also decreased linearly across quintiles of the dietary contribution from ultra-processed foods (from 14.9 to $11.6 \%$ of total energy) ${ }^{(51)}$. Being based on household purchasing data, that prior study and others based on the NOVA classification system ${ }^{(23,25,52-54)}$ could not evaluate fraction of wasted food nor purchases at restaurants, which represent a substantial proportion of US energy intake. A study carried out in Brazil with dietary consumption data from 2008-2009 also found a linear drop in protein content across quintiles of ultra-processed food consumption, from $19 \cdot 3$ to $14 \cdot 8 \%^{(55)}$. Our findings build upon and considerably extend these prior reports by evaluating food processing and protein intake using contemporary, nationally representative dietary intake data in the USA.

Our study has several strengths. We tested an a priori prediction of the PLH using data for a large, nationally representative sample of the US population, increasing generalizability. Our investigation was based on individual consumption data, rather than household purchasing data which do not evaluate the fraction of wasted food nor purchases at restaurants.

Potential limitations should be considered. As with most population dietary measures, data obtained by $24 \mathrm{~h}$ recalls are imperfect ${ }^{(56)}$, although the standardized methods and approach of NHANES and use of two recalls per person minimize potential error and bias. Even though some authors have recommended not using self-reported energy intake as a measure of true energy intake ${ }^{(56,57)}$, it must be noted that the primary aim of the present study was not to estimate true energy intakes but rather differences in energy intake across levels of ultra-processed food consumption. Some people (e.g. obese) may underreport food intake ${ }^{(58,59)}$ and more specifically fat intake $\mathrm{e}^{(33,60)}$ or consumption of foods with caloric sweeteners $^{(61)}$ such as desserts and sweet baked goods ${ }^{(62,63)}$, which may lead to an underestimation of total energy intake or an overestimation of the percentage of energy contributed by protein. This might lead us to underestimate the association of the dietary contribution of ultraprocessed foods with energy intake if high consumers of ultra-processed foods tend to be overweight ${ }^{(64)}$ and these, in turn, tend to be under-reporters. If so, this sort of bias would only work against the PLH. Although NHANES collects some information indicative of food processing (i.e. place of meals, product brands), these data are not consistently determined for all food items which may result in errors in food group classification. Also, the number of food items reported in NHANES is smaller than 
the number available in the marketplace, and national food composition data are imprecise and not updated as required $^{(65)}$.

\section{Conclusion}

In conclusion, we found that ultra-processed foods have lower protein content when compared with both processed foods and unprocessed or minimally processed foods combined with processed culinary ingredients; and also that their dietary contribution is associated with reduced relative protein content in the diet. Consistent with the PLH, the dilution of the overall dietary protein content in the US diet by ultraprocessed foods is associated with higher total energy intake, while the absolute protein intake remains relatively constant. Therefore, reducing the contribution of ultraprocessed foods in the US diet may be an effective way to increase its dietary protein concentration and prevent excessive energy intake.

\section{Acknowledgements}

Financial support: This research received funding from Conselho Nacional de Desenvolvimento Científico e Tecnológico, Edital MCTI/CNPq/Universal (Processo CNPq $n^{\circ}$ 443477/2014-0) and from Fundação de Amparo à Pesquisa do Estado de São Paulo (Processo FAPESP no 2015/14900-9). CNPq and FAPESP had no role in the design analysis or writing of this article. Conflict of interest: All authors declare no potential conflicts of interest for the submitted work. Authorship: E.M.S. and C.A.M. designed the research; E.M.S., D.R., S.J.S., L.G.B. and C.A.M. analysed the data; E.M.S., D.R., S.J.S. and C.A.M. wrote the paper. All authors read and approved the final manuscript. Ethics of human subject participation: NHANES 2009-2010 underwent institutional review board approval and Included written informed consent.

\section{Supplementary material}

To view supplementary material for this article, please visit https://doi.org/10.1017/S1368980017001574

\section{References}

1. Scrinis G (2013) Nutritionism: The Science and Politics of Dietary Advice. New York: Columbia University Press.

2. Bray GA \& Popkin BM (1998) Dietary fat intake does affect obesity! Am J Clin Nutr 68, 1157-1173.

3. Stubbs RJ, Mazlan N \& Whybrow S (2001) Carbohydrates, appetite and feeding behavior in humans. J Nutr 131, issue 10, 2775S-2781S

4. Willet WC (1998) Dietary fat and obesity: an unconvincing relation. Am J Clin Nutr 68, 1149-1150.
5. Simpson SJ \& Raubenheimer D (2005) Obesity: the protein leverage hypothesis. Obes Rev 6, 133-142.

6. Food and Agriculture Organization of the United Nations (2002) FAOSTAT database. http://faostat.fao.org/faostat/ collections (accessed December 2015).

7. Westerterp-Plantenga MS (1994) Nutrient utilization and energy balance. In Food Intake and Energy Expenditure, pp. 311-319 [MS Westerterp-Platenga, EWHM Fredrix, AB Steffens et al., editors]. Boca Raton, FL: CRC Press.

8. Weigle DS, Breen PA, Matthys CC et al. (2005) A highprotein diet induces sustained reductions in appetite, ad libitum caloric intake, and body weight despite compensatory changes in diurnal plasma leptin and ghrelin concentrations. Am J Clin Nutr 82, 41-48.

9. Astrup A, Raben A \& Geiker N (2015) The role of higher protein diets in weight control and obesity-related comorbidities. Int J Obes (Lond) 39, 721-726.

10. Raubenheimer D \& Simpson SJ (1997) Integrative models of nutrient balancing: application to insects and vertebrates. Nutr Res Rev 10, 151-179.

11. Kyriazakis I, Emmans GC \& Whittemore CT (1991) The ability of pigs to control their protein intake when fed in three different ways. Physiol Behav 50, 1197-1203.

12. Webster AJ (1993) Energy partitioning, tissue growth and appetite control. Proc Nutr Soc 52, 69-76.

13. Simpson SJ \& Raubenheimer D (2012) The Nature of Nutrition: A Unifying Framework from Animal Adaptation to Human Obesity. Princeton, NJ: Princeton University Press.

14. Raubenheimer D, Machovsky-Capuska GE, Gosby AK et al. (2014) Nutritional ecology of obesity: from humans to companion animals. Br J Nutr 113, Suppl., S26-S39.

15. Gosby AK, Conigrave AD, Raubenheimer D et al. (2014) Protein leverage and energy intake. Obes Rev 15, 183-191.

16. Gosby AK, Conigrave AD, Lau NS et al. (2011) Testing protein leverage in lean humans: a randomised controlled experimental study. PLoS One 6, e25929.

17. Campbell CP, Raubenheimer D, Badaloo AV et al. (2016) Developmental contributions to macronutrient selection: a randomized controlled trial in adult survivors of malnutrition. Evol Med Public Health 2016, 158-169.

18. Martens EA, Lemmens SG \& Westerterp-Plantenga MS (2013) Protein leverage affects energy intake of high-protein diets in humans. Am J Clin Nutr 97, 86-93.

19. Austin GL, Ogden LG \& Hill JO (2011) Trends in carbohydrate, fat, and protein intakes and association with energy intake in normal weight, overweight, and obese individuals: 1971-2006. Am J Clin Nutr 93, 836-843.

20. Stuckler D, McKee M, Ebrahim S et al. (2012) Manufacturing epidemics: the role of global producers in increased consumption of unhealthy commodities including processed foods, alcohol, and tobacco. PLoS Med 9, e1001235.

21. Monteiro CA \& Cannon G (2012) The impact of transnational 'Big Food' companies on the South: a view from Brazil. PLoS Med 9, e1001252.

22. Moodie R, Stuckler D, Monteiro C et al.; Lancet NCD Action Group (2013) Profits and pandemics: prevention of harmful effects of tobacco, alcohol, and ultra-processed food and drink industries. Lancet 381, 670-679.

23. Monteiro CA, Moubarac JC, Cannon G et al. (2013) Ultra-processed products are becoming dominant in the global food system. Obes Rev 14, Suppl. 2, 21-28.

24. Pan American Health Organization (2015) Ultra-Processed Food and Drink Products in Latin America: Trends, Impact on Obesity, Policy Implications. Washington, DC: PAHO.

25. Monteiro CA, Levy RB, Claro RM et al. (2010) A new classification of foods based on the extent and purpose of their processing. Cad Saude Publica 26, 2039-2049. 
26. Monteiro CA, Cannon G, Levy RB et al. (2015) Ultra-processing and a new classification of foods. In Introduction to US Food System. Public Health, Environment, and Equity, pp. 338-339 [R Neff, editor]. San Francisco, CA: Jossey-Bass.

27. Food and Agriculture Organization of the United Nations (2015) Guidelines on the Collection of Information on Food Processing Through Food Consumption Surveys. Rome: FAO.

28. Brooks RC, Simpson SJ \& Raubenheimer D (2010) The price of protein: combining evolutionary and economic analysis to understand excessive energy consumption. Obes Rev 11, 887-894.

29. Centers for Disease Control and Prevention National Center for Health Statistics (n.d.) National Health and Nutrition Examination Survey. https://wwwn.cdc.gov/nchs/nhanes/continuous nhanes/default.aspx?BeginYear=2009 (accessed September 2017).

30. Johnson CL, Paulose-Ram R, Ogden CL et al. (2013) National Health and Nutrition Examination Survey: analytic guidelines, 1999-2010. Vital Health Stat 2, issue 161, 1-24.

31. Centers for Disease Control and Prevention, National Center for Health Statistics (2009) National Health and Nutrition Examination Survey. MEC In-Person Dietary Interviewers Procedures Manual. https://www.cdc.gov/nchs/data/nhanes/ nhanes_09_10/mec_in_person_dietary_procedures_manual_ mar_2010.pdf (accessed September 2017).

32. Centers for Disease Control and Prevention, National Center for Health Statistics (2009) National Health and Nutrition Examination Survey. Phone Follow-Up Dietary Interviewer Procedures Manual. https://www.cdc.gov/nchs/data/nhanes/ nhanes_09_10/phone_follow_up_dietary_procedures_manual_ mar_2010.pdf (accessed September 2017).

33. Moshafegh AJ, Rhodes DG, Baer DJ et al. (2008) The USDA Automated Multiple-Pass Method reduces bias in the collection of energy intakes. Am J Clin Nutr 88, 324-332.

34. Blanton CA, Moshfegh AJ, Baer DJ et al. (2006) The USDA Automated Multiple-Pass Method accurately estimates group total energy and nutrient intake. $J$ Nutr 136, 2594 2599.

35. Rumpler WV, Kramer M, Rhodes DG et al. (2008) Identifying sources of reporting error using measured food intake. Eur J Clin Nutr 62, 544-552.

36. US Department of Agriculture, Agricultural Research Service (n.d.) Automated Multiple-Pass Method. http://www.ars. usda.gov/ba/bhnrc/fsrg (accessed September 2017).

37. Centers for Disease Control and Prevention National Center for Health Statistics (n.d.) National Health and Nutrition Examination Survey. NHANES Response Rates and Population Totals. Response Rates, http://www.cdc.gov/nchs/ nhanes/response_rates_CPS.htm (accessed September 2017).

38. Centers for Disease Control and Prevention National Center for Health Statistics (n.d.) National Health and Nutrition Examination Survey. 2009-2010 Data Documentation, Codebook, and Frequencies. https://wwwn.cdc.gov/nchs/nhanes/search/ datapage.aspx?Component=Dietary \&CycleBeginYear=2009 (accessed September 2017).

39. Moubarac JC, Parra DC, Cannon G et al. (2014) Food classification systems based on food processing: significance and implications for policies and actions: a systematic literature review and assessment. Curr Obes Rep 3, 256-272.

40. Martinez Steele E, Baraldi LG, Louzada ML et al. (2016) Ultra-processed foods and added sugars in the US diet: evidence from a nationally representative crosssectional study. BMJ Open 6, e009892.

41. Monteiro CA (2009) Nutrition and health. The issue is not food, nor nutrients, so much as processing. Public Health Nutr 12, 729-731.

42. Ludwig DS (2011) Technology, diet, and the burden of chronic disease. JAMA 305, 1352-1353.
43. Monteiro CA, Cannon G, Levy RB et al. (2012) The Food System. Processing. The big issue for disease, good health, well-being. World Nutr 3, 527-569.

44. Ahuja JKA, Montville JB, Omolewa-Tomobi G et al. (2012) USDA Food and Nutrient Database for Dietary Studies, 5.O. Beltsville, MD: US Department of Agriculture, Agricultural Research Service, Food Surveys Research Group.

45. US Department of Agriculture, Agricultural Research Service (2011) USDA National Nutrient Database for Standard Reference, Release 24. Nutrient Data Laboratory Home Page. http://www.ars.usda.gov/ba/bhnrc/ndl (accessed September 2017).

46. Barros AJ \& Hirakata VN (2003) Alternatives for logistic regression in cross-sectional studies: an empirical comparison of models that directly estimate the prevalence ratio. BMC Med Res Methodol 3, 21.

47. US Department of Health and Human Services \& US Department of Agriculture (2015) 2015-2020 Dietary Guidelines for Americans, 8th ed. http://health.gov/ dietaryguidelines/2015/guidelines/ (accessed September 2017).

48. Solon-Biet SM, Mitchell SJ, de Cabo R et al. (2015) Macronutrients and caloric intake in health and longevity. J Endocrinol 226, R17-R28.

49. Eicher-Miller HA, Fulgoni VL III \& Keast DR (2012) Contributions of processed foods to dietary intake in the US from 2003-2008: a report of the Food and Nutrition Science Solutions Joint Task Force of the Academy of Nutrition and Dietetics, American Society for Nutrition, Institute of Food Technologists, and International Food Information Council. J Nutr 142, issue 11, 2065S-2072S.

50. International Food Information Council Foundation (2010) Understanding our food communications tool kit. http:// www.foodinsight.org/For-Professionals/Understanding-OurFood/tabid/1398/Default.aspx (accessed September 2017).

51. Moubarac J-C, Martins APB, Claro RM et al. (2013) Consumption of ultra-processed foods and likely impact on human health. Evidence from Canada. Public Health Nutr 16, 2240-2248.

52. Monteiro CA, Levy RB, Claro RM et al. (2011) Increasing consumption of ultra-processed foods and likely impact on human health: evidence from Brazil. Public Health Nutr 14, $5-13$.

53. Crovetto M M, Uauy R, Martins AP et al. (2014) Household availability of ready-to-consume food and drink products in Chile: impact on nutritional quality of the diet. Rev Med Chil 142, 850-858.

54. Canella DS, Levy RB, Martins APB et al. (2014) Ultraprocessed food products and obesity in Brazilian households (2008-2009). PLoS One 9, e92752.

55. Louzada ML, Martins AP, Canella DS et al. (2015) Ultraprocessed foods and the nutritional dietary profile in Brazil. Rev Saude Publica 49, 38.

56. Subar AF, Freedman LS, Tooze JA et al. (2015) Addressing current criticism regarding the value of self-report dietary data. J Nutr 145, 2639-2645.

57. Dhurandhar NV, Schoeller D \& Brown AW (2015) Energy balance measurement: when something is not better than nothing. Int J Obes (Lond) 39, 1109-1113.

58. Murakami K \& Livingstone MBE (2015) Prevalence and characteristics of misreporting of energy intake in US adults: NHANES 2003-2012. Br J Nutr 114, 1294-1303.

59. Murakami K \& Livingstone MBE (2016) Prevalence and characteristics of misreporting of energy intake in US children and adolescents: National Health and Nutrition Examination Survey (NHANES) 2003-2012. Br J Nutr 115, 294-304.

60. Livingstone MB \& Black AE (2003) Markers of the validity of reported energy intake. J Nutr 133, Suppl., 3, 895S-920S. 
61. Bingham S, Luben R, Welch A et al. (2007) Epidemiologic assessment of sugars consumption using biomarkers: comparisons of obese and non-obese individuals in the European Prospective Investigation of Cancer Norfolk. Cancer Epidemiol Biomarkers Prev 16, 1651-1654.

62. Lafay L, Mennen L, Basdevant A et al. (2000) Does energy intake underreporting involve all kinds of food or only specific food items? Results from the Fleurbaix Laventie Ville Sante (FLVS) study. Int J Obes Relat Metab Disord 24, 1500-1506.
63. Pryer JA, Vrijheid M, Nichols R et al. (1997) Who are the 'low energy reporters' in the dietary and nutritional survey of British adults? Int J Epidemiol 26, $146-154$

64. Louzada ML, Baraldi LG, Steele EM et al. (2015) Consumption of ultra-processed foods and obesity in Brazilian adolescents and adults. Prev Med 81, 9-15.

65. Slining MM, Yoon EF, Davis J et al. (2015) An approach to monitor food and nutrition from 'factory to fork'. J Acad Nutr Diet 115, 40-49. 